\title{
Beneficial effects of dark chocolate on exercise capacity in sedentary subjects: Underlying mechanisms:
}

\author{
A double blind, randomized, placebo controlled trial
}

\author{
Pam R. Taub ${ }^{a}$, Israel Ramirez-Sanchez ${ }^{a, c}$, Minal Patel ${ }^{b}$, Erin Higginbotham ${ }^{b}$, Aldo Moreno- \\ Ulloa $^{\mathrm{a}, \mathrm{c}, \mathrm{e}}$, Luis Miguel Román-Pintos ${ }^{\mathrm{d}}$, Paul Phillips ${ }^{\mathrm{a}}$, Guy Perkins ${ }^{\mathrm{a}}$, Guillermo Ceballos ${ }^{\mathrm{c}}$, \\ and Francisco Villarreal ${ }^{a}$ \\ aUniversity of California, San Diego, School of Medicine, Sección de Posgrado, México City, \\ México \\ bVA San Diego Healthcare System, Sección de Posgrado, México City, México \\ 'Escuela Superior de Medicina del Instituto Politécnico Nacional, Sección de Posgrado, México \\ City, México \\ dDepartamento de Medicina Interna, Hospital Civil de Guadalajara "Dr. Juan I. Menchaca" \\ eDepartamento de Innovación Biomédica, Centro de Investigación Científica y de Educación \\ Superior de Ensenada (CICESE), Baja California, México
}

\begin{abstract}
In heart failure patients the consumption of (-)-epicatechin ((-)-Epi)-rich cocoa can restore skeletal muscle (SkM) mitochondrial structure and decrease biomarkers of oxidative stress. However, nothing is known about its effects on exercise capacity and underlying mechanisms in normal, sedentary subjects. Twenty normal, sedentary subjects ( $\sim 50$ years old) were randomized to placebo or dark chocolate (DC) groups and consumed $20 \mathrm{~g}$ of the products for 3 months. Subjects underwent before and after treatment, bicycle ergometry to assess $\mathrm{VO}_{2}$ max and work, SkM biopsy to assess changes in mitochondrial density, function and oxidative stress and blood sampling to assess metabolic endpoints. Seventeen subjects completed the trial. In the DC group $(\mathrm{n}=9), \mathrm{VO}_{2}$ max increased (17\% increase, $\left.\mathrm{p}=0.056\right)$ as well as maximum work (watts) achieved $(\mathrm{p}=0.026)$ with no changes with placebo $(\mathrm{n}=8)$. The DC group evidenced increases in HDL levels $(\mathrm{p}=0.005)$ and decreased triglycerides $(\mathrm{p}=0.07)$. With $\mathrm{DC}, \mathrm{SkM}$ evidenced significant increases in protein levels for LKB1, AMPK and PGC1a and in their active forms (phosphorylated AMPK and LKB1) as well as in citrate synthase activity while no changes were observed in mitochondrial density. With DC, significant increases in SkM reduced glutathione levels and decreases in protein carbonylation were observed. Improvements in maximum work achieved and $\mathrm{VO}_{2}$ max may be due to DC activation of upstream control systems and enhancement of SkM mitochondria efficiency. Larger clinical studies are warranted to confirm these observations.
\end{abstract}

Address reprint requests to: Francisco Villarreal MD, PhD, Professor of Medicine, UCSD School of Medicine, 9500 Gilman Dr. BSB4028, La Jolla, CA 92093-0613J, tel (858) 534-3630, lab (858) 534-1317, fax (858) 534-0522, fvillarr@ ucsd.edu.

Effects of Dark Chocolate on Exercise Capacity, and Mitochondrial Structure and Function, https://clinicaltrials.gov/ct2/show/ NCT01671514 and ClinicalTrials.gov identifier NCT01671514

Conflict of interest: None declared. 


\section{Keywords}

Chocolate; cocoa; (-)-epicatechin; mitochondria; muscle; exercise

\section{Introduction}

Published studies indicate that the consumption of modest amounts of dark chocolate (DC) is associated with reductions in the incidence of cardiovascular diseases (CVD) including, heart failure ${ }^{1}$. Clinical studies using cocoa and/or DC in normal volunteers or subjects with CVD have reported improvements in peripheral and coronary vascular function, blood pressure, insulin resistance, inflammatory markers, memory and cognition ${ }^{2-10}$. Mechanisms underlying improvements in vascular physiology are thought to be due to increased nitric oxide levels and improved endothelial function, which can be replicated by the administration of (-)-epicatechin ((-)-Epi), which is the most abundant flavanol present in cacao ${ }^{11}$.

We have demonstrated the capacity of (-)-Epi-rich cocoa or pure (-)-Epi to favorably impact mitochondria under normal and pathological conditions. In a pilot study in patients with both heart failure and type 2 diabetes, 3 months supplementation with (-)-Epi rich-cocoa ( $100 \mathrm{mg}(-)$-Epi/day) induced a significant recovery of SkM mitochondrial cristae, structural/functional proteins and regulators of mitochondrial biogenesis ${ }^{12}$. A recovery of multiple markers of muscle structure (e.g. dystrophin) and regulators of differentiation such as MyoD was also noted ${ }^{13}$. Systems that regulate oxidative stress levels such as superoxide dismutase, catalase and reduced glutathione levels also recovered ${ }^{14}$. In animal models treated with pure (-)-Epi, improvements in mitochondria related endpoints, muscle and oxidative stress can be triggered leading to enhanced exercise capacity similar to that provided by moderate treadmill training ${ }^{15}$. However, no studies have examined the capacity of (-)-Epi-rich DC to enhance exercise capacity in sedentary human subjects and assess its impact on metabolic and oxidative stress control systems.

It is widely recognized that essential to the preservation of overall cardiometabolic health is the inclusion of regular physical activity. Current guidelines suggest that individuals perform at least $150 \mathrm{~min}$ of moderate exercise activity/week in order to achieve this goal. However, for subjects 50 years and over, physical activity can be limited by a variety of chronic degenerative diseases or conditions such as osteoarthritis and obesity. Thus, many of these subjects fail to engage in physical conditioning leading to a deterioration of cardiometabolic health. Therefore, there is great interest in identifying natural products/supplements and/or novel agents that may preserve and/or stimulate physical conditioning so as to mitigate the effects of inactivity ${ }^{16}$. In particular, the identification of foods and/or agents that can be provided in limited amounts (for foods to limit a caloric load) and with low or absent toxicity is of great interest. It is widely recognized that agents that activate upstream metabolic control systems such as AMPK and PGC1a are likely to trigger such effects 16,17 .

The objectives of this study were to assess in middle age, sedentary subjects, the effects of (-)-Epi-rich DC on exercise capacity and examine the underlying mechanisms focusing on 
well recognized, upstream metabolic control systems, mitochondria density, function as well as oxidative stress endpoints.

\section{Methods}

\section{Clinical information}

The study was double blinded and only the research coordinator had access to the patient key. The protocol was approved by UCSD's Institutional Review Board (IRB 111680) and all subjects provided informed consent. Inclusion criteria were a sedentary status (as per $\mathrm{VO}_{2} \max <30 \mathrm{~mL} / \mathrm{kg} / \mathrm{min}$ ), BMI of 27-32 and an age range of 40-75 years old. Based on a power analysis we estimated that an $n=10 /$ group would be sufficient to achieve statistical significance. A total of thirty subjects of either sex with no past medical history and no prescription medications were screened (Figure 1). Twenty subjects met inclusion criteria and were randomized to placebo $(n=10)$ or DC groups $(n=10)$. Exclusion criteria were the use of anticoagulation therapy, smokers or those who quit smoking $<1$ year prior to enrollment and pregnancy. Subjects were instructed to consume 2 squares of placebo or DC provided by The Hershey Company (total of $20 \mathrm{~g}$ and $\sim 100$ calories/day that represents about half of a typical commercial chocolate bar) for 3 months. The composition of the DC and placebo products is described in Table 1 . An independent group of subjects $(n=5)$ were dosed and samples were collected $2 \mathrm{~h}$ post-dosing (at approximate Cmax values) so as to optimize dosing in order to achieve total (-)-Epi blood metabolites levels in the range of $0.1-1 \mu \mathrm{M}$ where optimal effects appear to occur. ${ }^{18-21}$. Twenty $\mathrm{g} /$ day of DC provided such an approximate blood concentration. Total metabolite (-)-Epi plasma levels were measured in those patients using High Liquid Chromatography coupled to High Resolution Mass Spectrometry based on our previous published method ${ }^{19}$. All chocolate samples were wrapped using the same material and were of comparable physical appearance. All volunteers were instructed to remain sedentary during the duration of the study period. Subjects underwent measurements of body morphometrics, blood sampling and SkM biopsies from quadriceps femoris (left Vastus Lateralis) before and after (right Vastus Lateralis) 3 months DC or placebo consumption.

\section{Cardiopulmonary Exercise Protocol with Stationary Bicycle}

Cardiopulmonary exercise protocol with exhaled gas analysis was performed ${ }^{22}$. Caffeine and alcohol ingestion were prohibited for $18 \mathrm{~h}$ before the test. Breath by breath gas analysis was collected during ramped exercise on stationary bicycle. The Orca ${ }^{\circledR}$ cardiopulmonary exercise testing system with an Oxigraf ${ }^{\circledR}$ laser diode absorption spectroscopy oxygen sensor and a CardioPulmonary Technologies ${ }^{\circledR}$ pulsed non-dispersive infrared spectroscopy $\mathrm{CO}_{2}$ sensor was calibrated with a known gas mixture before each gas collection. In each subject, we measured indicators of aerobic function including $\mathrm{VO}_{2}$ max.

\section{Electron microscopy (EM)}

As previously reported ${ }^{12}$, muscle samples were fixed in $2 \%$ paraformaldehyde plus $2.5 \%$ glutaraldehyde (Ted Pella, Redding, CA, USA) in $0.1 \mathrm{M}$ sodium cacodylate (pH 7.4) on ice for $24 \mathrm{~h}$ and processed for EM (supplemental material). 


\section{Reduced (GSH) and oxidized (GSSG) glutathione}

SkM samples $(25 \mathrm{mg})$ were homogenized with a polytron in $250 \mu \mathrm{L}$ of cold buffer $(50 \mathrm{mM}$

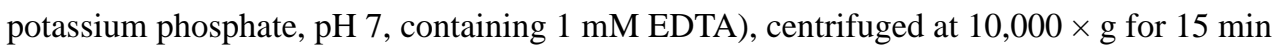
at $4{ }^{\circ} \mathrm{C}^{14}$. Supernatants were deproteinated and processed as described in supplemental material.

\section{Protein carbonylation}

Approximately $50 \mathrm{mg}$ of SkM was rinsed with PBS pH $7.4^{14}$. Tissue was homogenized in 1 $\mathrm{ml}$ of cold buffer (50 mM MES pH 6.7, containing $1 \mathrm{mM}$ EDTA). Homogenates were centrifuged at $10,000 \mathrm{~g}$ for $15 \mathrm{~min}$ at $4{ }^{\circ} \mathrm{C}$ then, supernatants were recovered and processed as described in supplemental material.

\section{Western blotting}

Approximately $25 \mathrm{mg}$ of SkM were homogenized with a polytron in $500 \mu \mathrm{l}$ lysis buffer (1\% Triton X-100, $20 \mathrm{mM}$ Tris, $140 \mathrm{mM} \mathrm{NaCl}, 2 \mathrm{mM}$ EDTA, and 0.1\% SDS) with protease and phosphatase inhibitor cocktails (P2714 and P2850, Sigma-Aldrich), supplemented with 0.15 $\mathrm{mM}$ phenylmethylsulfonyl fluoride, $5 \mathrm{mM} \mathrm{Na}_{3} \mathrm{VO}_{4}$ and $3 \mathrm{mM} \mathrm{NaF}^{12}$. Homogenates were sonicated $10 \mathrm{~min}$ at $4^{\circ} \mathrm{C}$ and centrifuged $12,000 \mathrm{~g}$ for $10 \mathrm{~min}$. Total protein content was measured in the supernatant using the Bradford method and then processed as described in supplemental material.

\section{Citrate synthase (CS) activity}

As a measure of mitochondrial function we evaluated CS activity ${ }^{15}$. SkM tissue samples (25 $\mathrm{mg}$ ) were homogenized with a polytron in $250 \mu \mathrm{L}$ of cold extraction buffer $(20 \mathrm{mM}$ Tris$\mathrm{HCl}, 140 \mathrm{mM} \mathrm{NaCl}, 2 \mathrm{mM}$ EDTA, and $0.1 \%$ sodium dodecyl sulfate) with protease inhibitors (P2714, Sigma-Aldrich), $5 \mathrm{mM} \mathrm{Na}_{3} \mathrm{VO}_{4}$, and $3 \mathrm{mM} \mathrm{NaF}$. Homogenates were centrifuged at $10,000 \times \mathrm{g}$ for $15 \mathrm{~min}$ at $4^{\circ} \mathrm{C}$. Supernatants were recovered and used to measure CS activity (supplemental material).

\section{Statistical analysis}

A paired t-test or when appropriate a non-parametric analysis was used to compare differences observed before vs. after. Table 3 values are reported as mean \pm SD. Otherwise, all other values reported are mean \pm SEM. Statistical significance was defined when $\mathrm{P}<0.05$.

\section{Results}

Two subjects from the placebo and one from de DC groups failed to complete the study for reasons not related to treatment (Figure 1). Subjects reported no adverse effects with treatment. General baseline subject characteristics are noted in Table 2. At the beginning of the study, demographic and anthropometric parameters were similar in the placebo and DC groups. No differences were noted in body weight amongst groups after treatment. The analysis of blood chemistry yielded a significant, $~ 10 \%$ increase in HDL values (from a mean value of 48.8 to $54 \mathrm{mg} / \mathrm{dL}, \mathrm{p}=0.005)$ in the $\mathrm{DC}$ group and a trend (109 to $89.8 \mathrm{mg} / \mathrm{dL}$, $\mathrm{p}=0.074$ ) for decreases in triglycerides (Table 3 ). For all other endpoints evaluated such as 
glucose, total cholesterol, LDL, c-reactive protein, $\mathrm{HbA}_{1 \mathrm{c}}$, no differences were detected in either groups.

Bicycle ergometry $\mathrm{VO}_{2}$ max values yielded no significant changes in the placebo group (Figure 2A). However, in the DC group there was a trend for an increase in $\mathrm{VO}_{2}$ max from $22.9 \pm 1.9$ to $25.7 \pm 1.4 \mathrm{ml} / \mathrm{kg} / \mathrm{min}$ ( $\mathrm{p}=0.056$ vs. before). However, when net changes per individual were compared, a significant ( $\mathrm{p}=0.043$ ) difference averaging $2.8 \pm 1.2 \mathrm{~mL} / \mathrm{kg} / \mathrm{min}$ was observed with DC whereas the placebo demonstrated no change (Figure 2B). The analysis of changes in power values (Figure 2C) yielded no differences in the placebo group while the DC increased from $140.7 \pm 11.6$ to $148.3 \pm 11$ watts $(\mathrm{p}=0.027)$.

The analysis of upstream metabolic control systems evidence no significant changes in total LKB1 protein levels in the placebo group (from $0.71 \pm 0.1$ to $0.66 \pm 0.1$ relative units, $\mathrm{p}>0.05$ ). However, significant increases were observed in the DC group (from $0.81 \pm 0.1$ to $0.96 \pm 0.07$ relative units, $\mathrm{p}=0.012$ ). As shown in Figure $3 \mathrm{~A}$, no significant changes were observed in p-LKB1 levels in the placebo group (normalized over total protein levels) whereas significant increases were noted with $\mathrm{DC}(\mathrm{p}=0.034)$. Similarly, the analysis of total AMPK protein levels in the placebo group (from $0.74 \pm 0.1$ to $0.72 \pm 0.07$ relative units, $\mathrm{p}>0.05$ ) did not yield differences while significant increases were noted in the DC group (from $0.75 \pm 0.06$ to $0.87 \pm 0.08$ relative units, $\mathrm{p}=0.02$ ). As shown in Figure $3 \mathrm{~B}$, in the placebo group p-AMPK levels (normalized over total protein levels) did not change while they increased with DC $(\mathrm{p}=0.023)$. The analysis of PGC1a total protein levels (Figure 3C) evidenced no significant changes in the placebo group with significant increases noted in the DC group ( $\mathrm{p}=0.007)$. The analysis of porin and mitofilin protein levels did not detect any differences in both groups with treatment (data not shown). The analysis of mitochondrial volume by EM did not evidence significant changes in either of the groups $(4.3 \pm 0.57$ vs. $7.2 \pm 2.1$ in placebo and $4.3 \pm 0.53$ vs. $5.2 \pm 0.88$ in DC) with treatment.

GSH is an important intracellular antioxidant and its levels can be impacted (decreased) in the setting of oxidative stress. Figure 4A illustrates the values recorded for GSH/GSSG levels. Whereas no differences were noted in the placebo group a significant increase was noted with DC ( $\mathrm{p}=0.003)$. Protein carbonylation was used as an indicator of oxidative stress levels. A significant reduction (Figure 4B) in carbonylation levels was only observed in the DC group ( $\mathrm{p}=0.001$ ). CS activity levels results are illustrated in Figure 5. As can be observed, no significant changes were noted in the placebo group (Figure 5A) whereas a significant ( $\sim 2.5$ fold, $\mathrm{p}=0.0002)$ increase in activity was noted with DC (Figure $5 \mathrm{~B}$ ).

\section{Discussion}

Unique findings from this study indicate that in sedentary, middle age subjects, the consumption of moderate amounts of DC can potentially lead to gains in exercise capacity measured as $\mathrm{VO}_{2}$ max and power. Such responses are linked to increases in SkM total protein and/or active (phosphorylated) levels for recognized upstream modulators of cellular metabolism. The positive effects triggered by such stimulation leads to apparent increases in mitochondria function and decreased oxidative stress. These effects are also accompanied by improvements in blood metabolic endpoints particularly, HDL. 
It is well recognized that physical conditioning (i.e. training) can positively impact SkM function leading to gains in $\mathrm{VO}_{2}$ max. Apparently, such effects can be triggered in subjects independently of their age, gender and sedentary status. In the HERITAGE study in healthy sedentary subjects 16-65 years old, increases in $\mathrm{VO}_{2}$ max with 20 weeks of aerobic conditioning averaged from $\sim 13-22 \%$ depending on the intensity of training ${ }^{23}$. Similar magnitudes of increases in $\mathrm{VO}_{2}$ max have been reported in other studies with aerobic training including $\sim 60$ years old subjects ${ }^{24}$. However, common chronic conditions or diseases in subjects 55 and older such as obesity or arthritis frequently limit or prevent the capacity of individuals to exercise. It is thus, essential that new strategies are identified which allow subjects to maintain, recover or improve muscle strength through viable and safe alternatives that can be sustained indefinitely. We previously evidenced the potential of (-)-Epi rich DC to exert restorative effects on SkM of heart failure and type 2 diabetes patients ${ }^{12}$. While the study was underpowered to provide statistical validation of potential effects on $\mathrm{VO}_{2}$ max, it did provide an indication as to possible positive effects on exercise capacity. Central to the effects observed in those patients were actions noted in mitochondrial endpoints and oxidative stress 12,14 . We also recently reported on a study using rodents where we demonstrated significant gains in exercise performance in animals treated orally with pure (-)-Epi for 2 weeks at a dose of $1 \mathrm{mg} / \mathrm{kg} /$ day ${ }^{15}$. Thus, we designed the current study to determine if in sedentary, middle age subjects discernible effects could be gained with 12 weeks of DC supplementation and if the outcome could be attributed to actions exerted on key regulators of cellular metabolism and in mitochondria.

A limited number of published studies have reported on the effects of natural compounds on exercise capacity. Compounds examined include quercetin, green tea catechins and resveratrol. These studies typically do not conform to a dosing scheme that is well justified but in many cases misguidedly follow the premise that "the more, the better" as they frequently attribute their potential effects to the compounds acting as simple antioxidants. Thus, in many studies "large" doses of such products are used. A meta-analysis of 11 studies using quercetin was recently reported ${ }^{25}$. The effect sizes calculated for all studies combining $\mathrm{VO}_{2}$ max and endurance performance measures indicated a significant effect favoring quercetin over placebo, but the magnitude of the effect was considered between trivial and small, equating to a $\sim 2 \%$ improvement. Using green tea catechins, eight male cyclists participated in a randomized, placebo-controlled, double-blinded study ${ }^{26}$. Cyclists received placebo or epigallocatechin gallate $(270 \mathrm{mg})$ over a 6-day period and $1 \mathrm{~h}$ before exercise finding little benefit in consuming the green-tea catechin on fat oxidation or cycling performance. Less is documented about the effects of resveratrol in humans. However, a recent study reported on the blunting effects of resveratrol on exercise conditioning in healthy $\sim 65$ years old men ${ }^{27}$. Exercise training alone, led to a $45 \%$ greater $(\mathrm{p}<0.05)$ increase in $\mathrm{VO}_{2}$ max in the placebo vs. the resveratrol-exercise groups. In concert with this observation, is the emerging consensus that the use of products with strong antioxidant properties (including vitamins such as $\mathrm{C}$ and $\mathrm{E}$ ) may actually impair exercise induced SkM conditioning ${ }^{28}$. Thus, the hypothesis that natural products can exert conditioning effects on SkM following their antioxidant potential is poorly supported ${ }^{10}$. As such, these actions are unlikely to account for the beneficial effects noted with DC. 
Upstream mechanisms that may explain the effects of DC remain to be identified. We have provided indirect and direct evidence as to the possible existence of cell surface $\mathrm{G}$ proteincoupled receptors (i.e. the G protein-coupled estrogen receptor) for (-)-Epi $20,21,29$. It is therefore plausible that (-)-Epi, by binding to such receptors may activate signaling pathways that can exert positive effects on metabolic control systems. For this study, we selected a dose of DC that would yield average total (-)-Epi blood metabolite levels in the range of 0.1-1 $\mu \mathrm{M}$. We have previously reported that peak effects on cultured cells can be triggered within this dosing range ${ }^{21}$. PGC1a, is a key regulatory factor involved in the coordination of nuclear gene activation that encodes for mitochondrial proteins in multiple tissues including $\mathrm{SkM}^{30}$. In this regard, published exercise based studies provide a framework for examining candidate regulatory systems that can be contrasted with the results obtained from this study. In 2003, the first report emerged as to the induction of PGC1a transcription by physical training of human subjects ${ }^{31}$. A recent study by Konopka et al, reported on increases in PGCla SkM (Vastus Lateralis) protein levels in young ( 20) and older ( 74) subjects subjected to aerobic training for 12 weeks of 62 and $55 \%$ respectively ${ }^{32}$. In our study, we observe increases that average $\sim 75 \%$. Central to the activation of PGCla is the potential upstream participation of various kinases in particular, AMPK and (potentially even further upstream) LKB1. Multiple lines of evidence indicate that AMPK plays a key role as a master metabolic regulator of SkM energy balance ${ }^{33}$. Interestingly, pharmacological activators of AMPK such as AICAR can mimic adaptations to exercise training in animals ${ }^{16}$. In humans, resistance as well as endurance training, increases SkM AMPK activity as evidenced by its phosphorylation or kinase like activity ${ }^{33}$. However, much less is known about effects of exercise training on protein levels. In our study, with DC we observe increases in both, the total amount of protein $(\sim 15 \%)$ and in its phosphorylated status ( $\sim 120 \%)$. Published findings indicate that LKB1 functions as a constitutively active component that can phosphorylate AMPK in response to metabolic stress ${ }^{34}$. In mice, knockout of LKB1 is associated with ablated AMPK activity in resting SkM and when AICAR is used, lack of LKB1 completely prevents its activation ${ }^{34}$. In a study published by Sriwijitkamol et al, acute exercise bouts failed to stimulate increases in SkM LKB1 protein or activity levels in lean, obese or diabetic subjects ${ }^{35}$. With DC, we observed both, increases in LKB1 protein levels ( 25\%) and in its phosphorylated levels $(\sim 52 \%)$. It is interesting to speculate that whereas AMPK in the setting of exercise may be activated by increases in SkM AMP levels (which are unlikely to occur with DC supplementation), LKB1 may act as one possible transducer of DC effects.

The activation of PGCla can lead to the stimulation of mitochondrial biogenesis (i.e. increases in organelle volume) ${ }^{36}$. With exercise in humans, increases in mitochondrial volume have been reported reaching up to $40 \%{ }^{37}$. In our study, we did not observe such effects. The lack of effects may reflect a lack of need for organelle replication to be induced as SkM is truly not being mechanically and energetically "stressed" to improve performance as with exercise. As such, the question arises as to the possible mechanism explaining improved $\mathrm{VO}_{2}$ max with DC. One possibility is that existing mitochondria become more "efficient". To explore this possibility using CS as a surrogate, a 140\% increase in enzymatic activity was noted, suggesting that the organelle's bioenergetics metabolism had notably improved. Similar gains (albeit of lesser magnitude) have been reported in studies using 
physical conditioning. In a study by Jacobs et al, high intensity interval training led to significant improvements in exercise capacity accompanied by increases of $20 \%$ in SkM CS activity ${ }^{38}$. In a report by Short et al, aerobic exercise conditioning led to an increase in SkM CS activity of $\sim 45 \%{ }^{39}$. Thus, DC appears to be a very effective positive modulator of SkM CS activity, which may reflect unique (yet to be identified) effects on mitochondria.

As mitochondrial efficiency improves, it will likely positively impact tissue oxidative stress levels ${ }^{40}$. We utilized two well-accepted markers of oxidative stress, GSH/GSSG ratio and protein carbonylation levels to assess their changes in placebo and DC supplemented subjects. With DC, significant positive effects were noted in both endpoints. Olensen et al, reported that human subjects (60-72 years old) subjected to high-intensity exercise training a $20 \%$ decrease in SkM protein carbonylation was observed which is similar in magnitude to that observed by us with DC ${ }^{41}$. Svensson et al, reported that endurance training of human subjects led to adaptive increases in SkM GSH levels following a period of short-term training whereas transient reductions can be observed in the very immediate post-training period ${ }^{42}$. Thus, DC appears to exert similar effects to those of physical conditioning when provided over a sustained period of time. The mechanisms underlying these actions may be related to the transcriptional activation of relevant reactive oxygen species buffering systems (e.g. superoxide dismutase, catalase) as previously reported by us in heart failure patients ${ }^{14}$. However, we cannot exclude possible acute actions of DC on other relevant systems such as NOX2 as reported by others ${ }^{43}$. Altogether, results from this study indicate that DC appears to positively impact multiple up- and downstream control systems involved in cellular bioenergetics and metabolism suggesting conditioning-like effects of DC that apparently can translate into improvements in exercise capacity. Remarkably, these changes were induced in the absence of any physical conditioning as the subjects remained sedentary during the duration of the study.

Decreased mobility typically yields a deconditioning effect on SkM that may also foster (in particular, in older subjects) a sedentary lifestyle. It is interesting to speculate if the regular consumption of modest amounts of DC may favor a more active lifestyle. If such as scenario develops, the combination of DC effects with greater physical activity over time, may yield even greater benefits on the endpoints measured. An alternate scenario would encompass adding physical conditioning in combination with DC supplementation. Such regimen may lead to a substantial increase in benefits as we reported in our mouse study whereby we combined a moderate regimen of training with pure (-)-Epi supplementation ${ }^{15}$. Such studies are worthy of future rigorous investigations.

\section{Limitations}

There are several limitations associated with this study. One is the limited number of subjects enrolled, which may explain the marginal $(\mathrm{p}=0.056)$ inability to reach statistical significance in $\mathrm{VO}_{2}$ max in contrast to that achieved with power ( $\left.\mathrm{p}=0.027\right)$. Nonetheless, this study provides provocative initial evidence for potential positive effects on SkM on exercise capacity that can further explored in larger studies preferably using a crossover design. Given the effects on mitochondria, actions may be also exerted on muscle fatigue that can be further explored using properly designed studies to test for such endpoints. There is an 
important difference between placebo and DC composition, which relates to caffeine and theobromine content. It is possible that the effects reported may be partly attributable to the action of methylxanthines which, can be tested in future studies. However, the results of this study are in concert with the actions reported in our previous publications using pure (-)Epi ${ }^{15}$.

\section{Conclusions}

Treatment of sedentary subjects with DC improves HDL cholesterol in association with upstream regulators of SkM metabolic control. There were improvements in exercise capacity, which may be due to DC enhancement of SkM mitochondria efficiency. Larger studies are warranted to confirm these observations.

\section{Supplementary Material}

Refer to Web version on PubMed Central for supplementary material.

\section{Acknowledgments}

This study was supported by NIH grants DK98717, DK92154, to Dr. Villarreal. The Hershey® Company provided the products used and financial support for the study. Drs. Ceballos and Villarreal are stockholders in Cardero Therapeutics Inc.

\section{References}

1. Buitrago-Lopez A, Sanderson J, Johnson L, Warnakula S, Wood A, Di Angelantonio E, Franco OH. BMJ. 2011; 343:d4488. [PubMed: 21875885]

2. Buijsse B, Feskens EJ, Kok FJ, Kromhout D. Arch Intern Med. 2006; 166:411-417. [PubMed: 16505260]

3. Corti R, Flammer AJ, Hollenberg NK, Luscher TF. Circulation. 2009; 119:1433-1441. [PubMed: 19289648]

4. Heiss C, Dejam A, Kleinbongard P, Schewe T, Sies H, Kelm M. JAMA. 2003; 290:1030-1031. [PubMed: 12941674]

5. Heiss C, Kleinbongard P, Dejam A, Perre S, Schroeter H, Sies H, Kelm M. J Am Coll Cardiol. 2005; 46:1276-1283. [PubMed: 16198843]

6. Scholey AB, French SJ, Morris PJ, Kennedy DO, Milne AL, Haskell CF. J Psychopharmacol. 24:1505-1514. [PubMed: 19942640]

7. Desideri G, Kwik-Uribe C, Grassi D, Necozione S, Ghiadoni L, Mastroiacovo D, Raffaele A, Ferri L, Bocale R, Lechiara MC, Marini C, Ferri C. Hypertension. 2012; 60:794-801. [PubMed: 22892813]

8. Grassi D, Desideri G, Necozione S, di Giosia P, Barnabei R, Allegaert L, Bernaert H, Ferri C. J Hypertens. 2015; 33:294-303. [PubMed: 25380152]

9. Grassi D, Necozione S, Lippi C, Croce G, Valeri L, Pasqualetti P, Desideri G, Blumberg JB, Ferri C. Hypertension. 2005; 46:398-405. [PubMed: 16027246]

10. Hollman PC, Cassidy A, Comte B, Heinonen M, Richelle M, Richling E, Serafini M, Scalbert A, Sies H, Vidry S. J Nutr. 2011; 141:989S-1009S. [PubMed: 21451125]

11. Schroeter H, Heiss C, Balzer J, Kleinbongard P, Keen CL, Hollenberg NK, Sies H, Kwik-Uribe C, Schmitz HH, Kelm M. Proc Natl Acad Sci U S A. 2006; 103:1024-1029. [PubMed: 16418281]

12. Taub P, Ramirez-Sanchez I, Ciaraldi T, Perkins G, Murphy A, Naviaux R, Hogan M, Maisel A, Henry R, Ceballos G, Villarreal F. Clin Trans Sci. 2011; 5:43-47. 
13. Taub PR, Ramirez-Sanchez I, Ciaraldi TP, Gonzalez-Basurto S, Coral-Vazquez R, Perkins G, Hogan M, Maisel AS, Henry RR, Ceballos G, Villarreal F. Clin Sci (Lond). 2013; 125:383-389. [PubMed: 23642227]

14. Ramirez-Sanchez I, Taub PR, Ciaraldi TP, Nogueira L, Coe T, Perkins G, Hogan M, Maisel AS, Henry RR, Ceballos G, Villarreal F. Int J Cardiol. 2013; 168:3982-3990. [PubMed: 23870648]

15. Nogueira L, Ramirez-Sanchez I, Perkins G, Murphy A, Taub P, Ceballos G, Villarreal F, Hogan M, Malek M. Journal of Physiology. 2011; 589:4615-4631. [PubMed: 21788351]

16. Narkar VA, Downes M, Yu RT, Embler E, Wang YX, Banayo E, Mihaylova MM, Nelson MC, Zou Y, Juguilon H, Kang H, Shaw RJ, Evans RM. Cell. 2008; 134:405-415. [PubMed: 18674809]

17. Canto C, Auwerx J. Curr Opin Lipidol. 2009; 20:98-105. [PubMed: 19276888]

18. Taub PR, Ramirez-Sanchez I, Ciaraldi TP, Perkins G, Murphy AN, Naviaux R, Hogan M, Maisel AS, Henry RR, Ceballos G, Villarreal F. Clin Transl Sci. 2012; 5:43-47. [PubMed: 22376256]

19. Barnett CF, Moreno-Ulloa A, Shiva S, Ramirez-Sanchez I, Taub PR, Su Y, Ceballos G, Dugar S, Schreiner G, Villarreal F. Food Funct. 2015; 6:824-833. [PubMed: 25598082]

20. Moreno-Ulloa A, Mendez-Luna D, Beltran-Partida E, Castillo C, Guevara G, Ramirez-Sanchez I, Correa-Basurto J, Ceballos G, Villarreal F. Pharmacol Res. 2015; 100:309-320. [PubMed: 26303816]

21. Ramirez-Sanchez I, Maya L, Ceballos G, Villarreal F. Hypertension. 2010; 55:1398-1405. [PubMed: 20404222]

22. Phillips PS, Phillips CT, Sullivan MJ, Naviaux RK, Haas RH. Atherosclerosis. 2004; 177:183-188. [PubMed: 15488882]

23. Skinner JS, Wilmore KM, Krasnoff JB, Jaskolski A, Jaskolska A, Gagnon J, Province MA, Leon AS, Rao DC, Wilmore JH, Bouchard C. Med Sci Sports Exerc. 2000; 32:157-161. [PubMed: 10647543]

24. Kohrt WM, Malley MT, Coggan AR, Spina RJ, Ogawa T, Ehsani AA, Bourey RE, Martin WH 3rd, Holloszy JO. J Appl Physiol (1985). 1991; 71:2004-2011. [PubMed: 1761503]

25. Kressler J, Millard-Stafford M, Warren GL. Med Sci Sports Exerc. 2011; 43:2396-2404. [PubMed: 21606866]

26. Dean S, Braakhuis A, Paton C. Int J Sport Nutr Exerc Metab. 2009; 19:624-644. [PubMed: 20175431]

27. Gliemann L, Schmidt JF, Olesen J, Bienso RS, Peronard SL, Grandjean SU, Mortensen SP, Nyberg M, Bangsbo J, Pilegaard H, Hellsten Y. J Physiol. 2013; 591:5047-5059. [PubMed: 23878368]

28. Paulsen G, Cumming KT, Holden G, Hallen J, Ronnestad BR, Sveen O, Skaug A, Paur I, Bastani NE, Ostgaard HN, Buer C, Midttun M, Freuchen F, Wiig H, Ulseth ET, Garthe I, Blomhoff R, Benestad HB, Raastad T. J Physiol. 2014; 592:1887-1901. [PubMed: 24492839]

29. Moreno-Ulloa A, Romero-Perez D, Villarreal F, Ceballos G, Ramirez-Sanchez I. Bioorg Med Chem Lett. 2014; 24:2749-2752. [PubMed: 24794111]

30. Scarpulla RC. Biochim Biophys Acta. 2002; 1576:1-14. [PubMed: 12031478]

31. Pilegaard H, Saltin B, Neufer PD. J Physiol. 2003; 546:851-858. [PubMed: 12563009]

32. Konopka AR, Suer MK, Wolff CA, Harber MP. J Gerontol A Biol Sci Med Sci. 2014; 69:371-378. [PubMed: 23873965]

33. Jessen N, Sundelin EI, Moller AB. Drug Discov Today. 2014; 19:999-1002. [PubMed: 24637044]

34. Jorgensen SB, Rose AJ. Front Biosci. 2008; 13:5589-5604. [PubMed: 18508608]

35. Sriwijitkamol A, Coletta DK, Wajcberg E, Balbontin GB, Reyna SM, Barrientes J, Eagan PA, Jenkinson CP, Cersosimo E, DeFronzo RA, Sakamoto K, Musi N. Diabetes. 2007; 56:836-848. [PubMed: 17327455]

36. Puigserver P. Int J Obes (Lond). 2005; 29(1):S5-9. [PubMed: 15711583]

37. Hoppeler H, Howald H, Conley K, Lindstedt SL, Claassen H, Vock P, Weibel ER. J Appl Physiol (1985). 1985; 59:320-327. [PubMed: 4030584]

38. Jacobs RA, Fluck D, Bonne TC, Burgi S, Christensen PM, Toigo M, Lundby C. J Appl Physiol (1985). 2013; 115:785-793. [PubMed: 23788574]

39. Short KR, Vittone JL, Bigelow ML, Proctor DN, Rizza RA, Coenen-Schimke JM, Nair KS. Diabetes. 2003; 52:1888-1896. [PubMed: 12882902] 
40. Cui H, Kong Y, Zhang H. J Signal Transduct. 2012; 2012:646354. [PubMed: 21977319]

41. Olesen J, Gliemann L, Bienso R, Schmidt J, Hellsten Y, Pilegaard H. J Physiol. 2014; 592:18731886. [PubMed: 24514907]

42. Svensson MB, Ekblom B, Cotgreave IA, Norman B, Sjoberg B, Ekblom O, Sjodin B, Sjodin A. Acta Physiol Scand. 2002; 176:43-56. [PubMed: 12193218]

43. Loffredo L, Perri L, Catasca E, Pignatelli P, Brancorsini M, Nocella C, De Falco E, Bartimoccia S, Frati G, Carnevale R, Violi F. J Am Heart Assoc. 2014; 3 


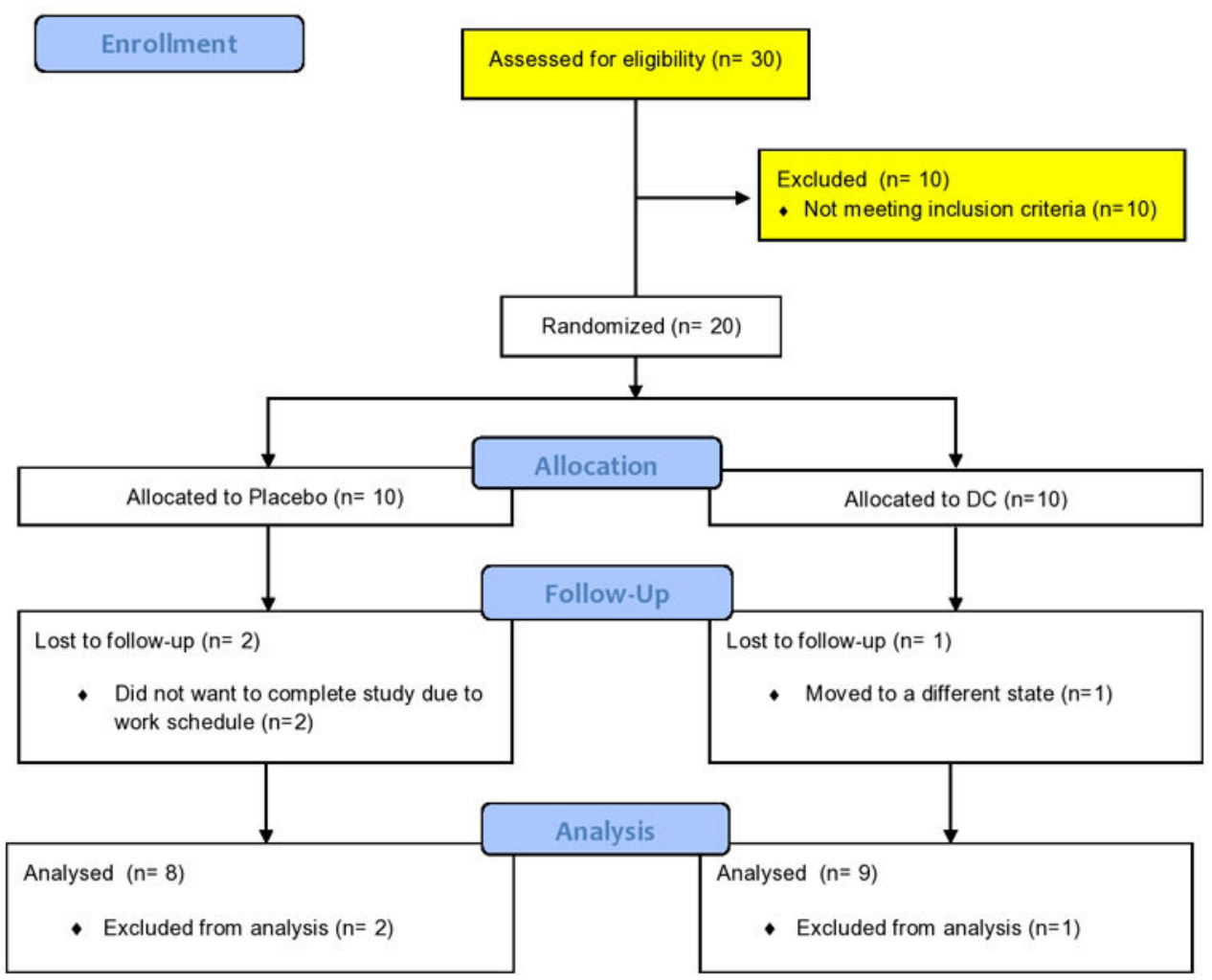

Figure 1.

Study design flowchart. DC, dark chocolate. 
A

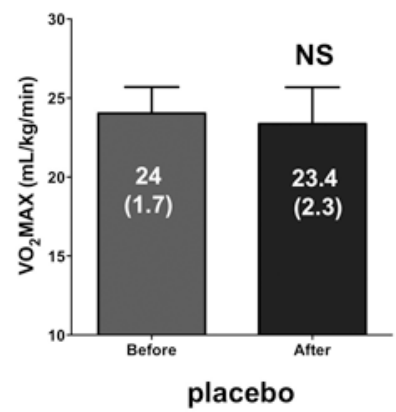

B

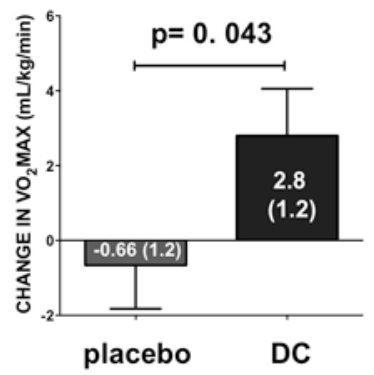

C

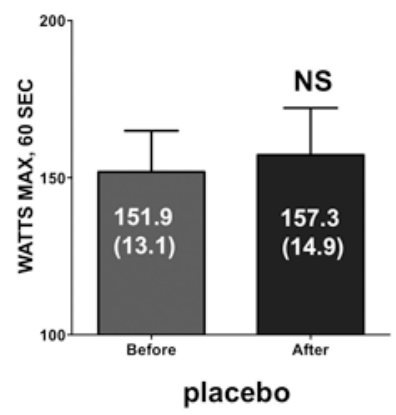

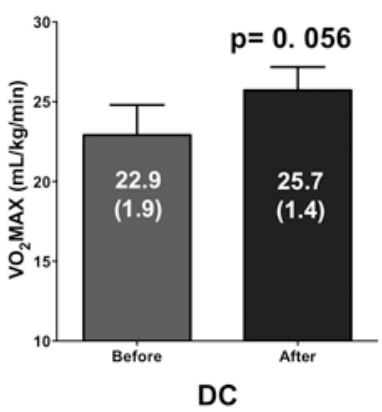

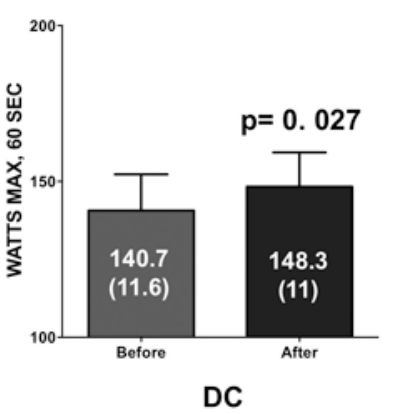

Figure 2.

Effects of 3 months of supplementation with placebo or dark chocolate (DC) on exercise capacity as recorded by cycle ergometry. $\mathrm{VO}_{2}$ max levels recorded for both groups (A). Averages are also presented for net change in $\mathrm{VO}_{2}$ max values per each individual (B). Changes in power values recorded in both groups (C). Values reported are mean \pm (SEM). A paired t-test was used to assess statistical significance. 

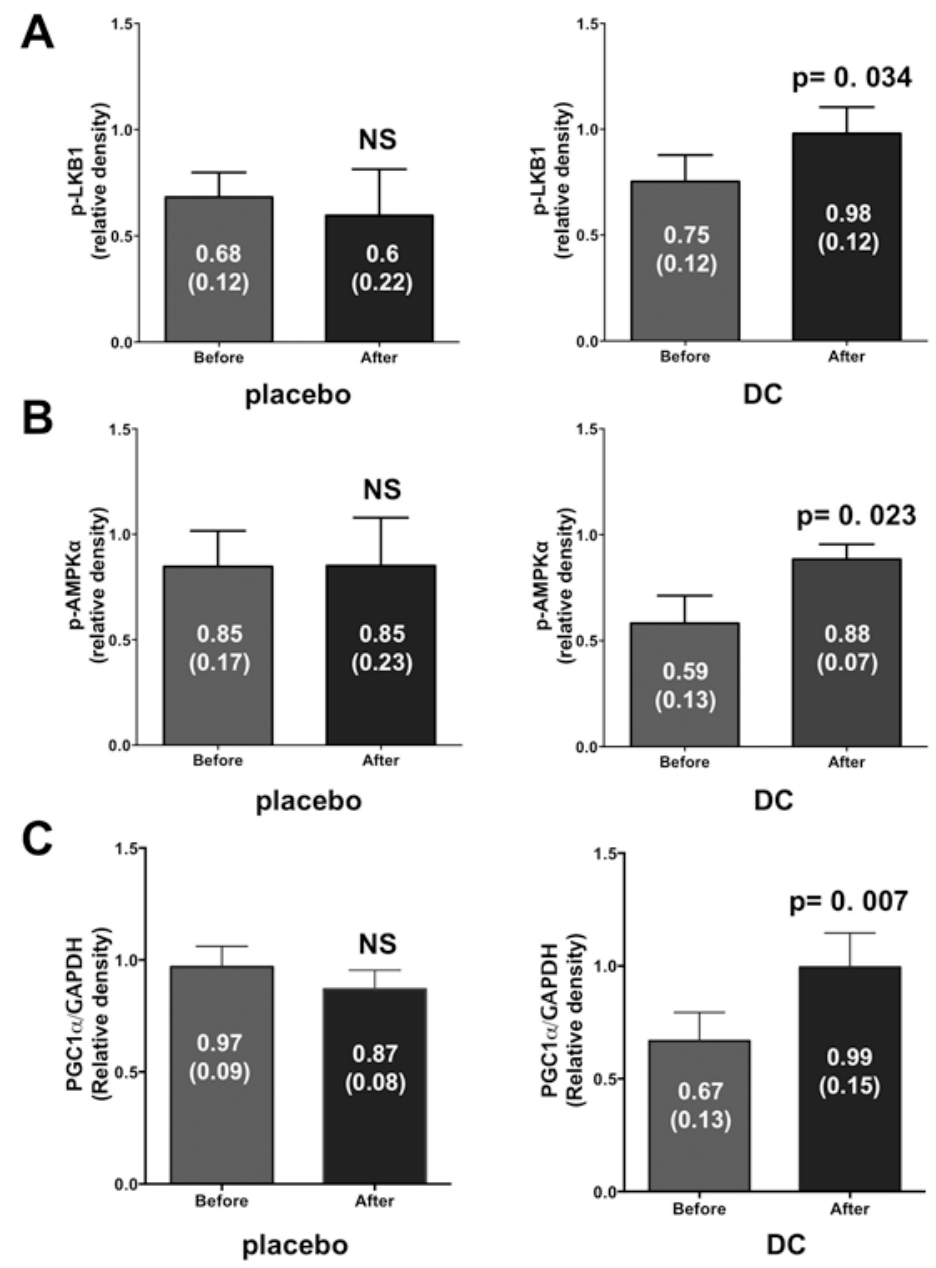

Figure 3.

Protein levels of metabolic regulators in skeletal muscle (SkM) biopsies as determined by Western blots. (A) SkM protein levels of phosphorylated (p) LKB1 before and after 3 month supplementation in the placebo and dark chocolate (DC) groups. p-LKB1 protein levels were normalized to total LKB1 protein values. (B) SkM protein levels of p-AMPK (normalized to AMPK protein levels) in the placebo and DC groups. (C) SkM protein levels of PGC1a in the placebo and DC groups. PGC1a protein levels were normalized to GAPDH protein values. Values reported are mean \pm (SEM). A paired t-test was used to assess statistical significance. 

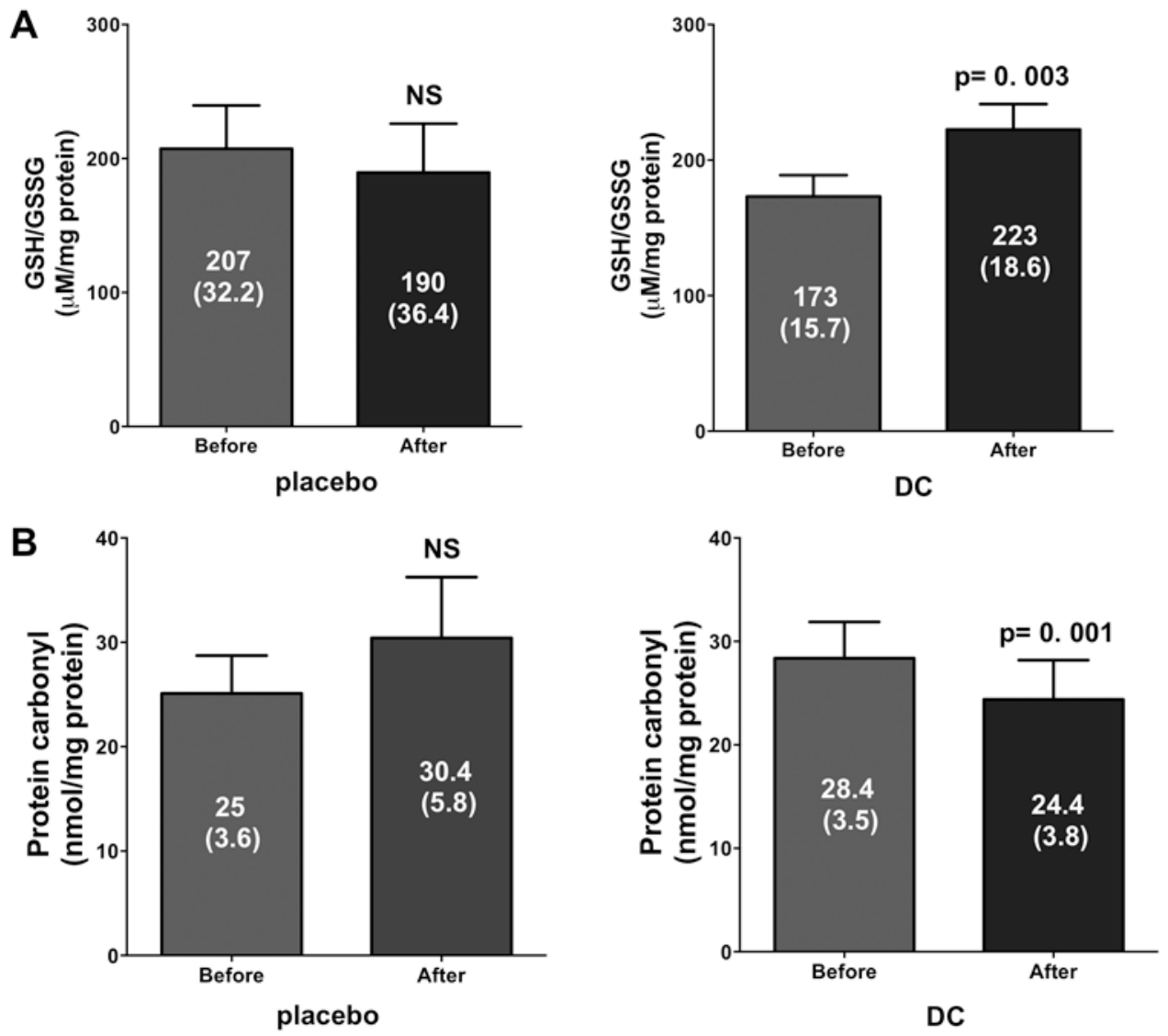

Figure 4.

Changes in indicators of tissue oxidative stress in skeletal muscle. (A) Reduced glutathione (GSH)/oxidized glutathione (GSSG) ratio and protein carbonylation levels (B) recorded in the placebo and dark chocolate (DC) groups after 3 months of supplementation. Values reported are mean $\pm(\mathrm{SEM})$. A paired t-test was used to assess statistical significance. 
A

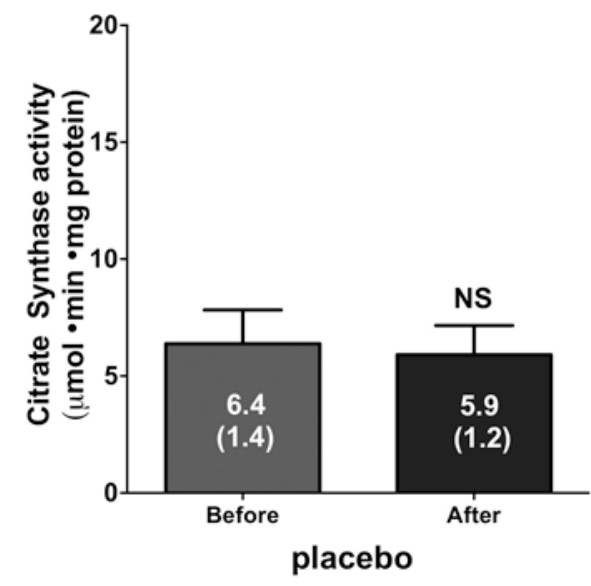

B

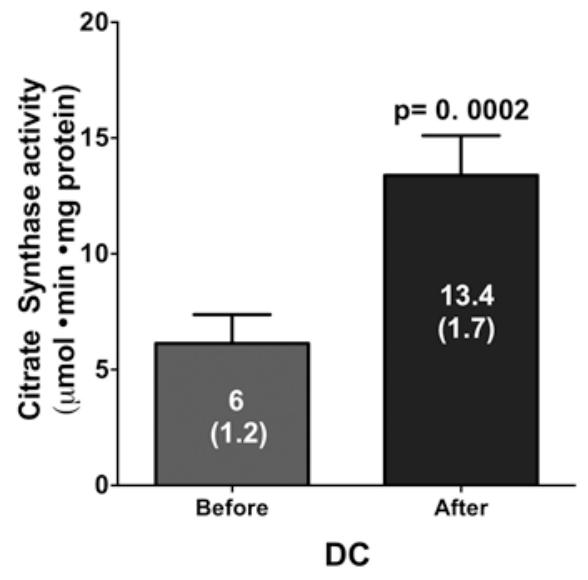

Figure 5.

Citrate synthase (i.e. mitochondrial) activity levels in skeletal muscle biopsies from the placebo and dark chocolate (DC) groups after 3 months of supplementation. Values reported are mean $\pm(\mathrm{SEM})$. A paired t-test was used to assess statistical significance. 
Table 1

Composition of the placebo and DC product used in the study per 20 gram serving

\begin{tabular}{|c|c|c|}
\hline Composition & Placebo & DC \\
\hline Cocoa flavanols, monomers-decamers, $\mathrm{mg}$ & 1.2 & 175.2 \\
\hline Monomers, mg & 0.4 & 30.6 \\
\hline (-)-epicatechin & 0.3 & 26 \\
\hline$(+)$-catechin & 0.1 & 4.6 \\
\hline Caffeine & 2 & 13 \\
\hline Theobromine & 18 & 128 \\
\hline Energy, kcal & 90 & 100 \\
\hline Fat, $\mathrm{g}$ & 6 & 7 \\
\hline Carbohydrate, g & 12.25 & 10.5 \\
\hline Protein, g & 1 & 1.5 \\
\hline
\end{tabular}

$\mathrm{DC}=$ dark chocolate 
Table 2

General baseline characteristics of subjects studied

\begin{tabular}{cccc}
\hline General characteristics & Placebo $(\mathbf{n}=\mathbf{8})$ & Dark chocolate $(\mathbf{n}=9)$ & $\mathbf{p}$ Value \\
\hline $\mathrm{Sex}(\mathrm{M} / \mathrm{F}), \mathrm{n}$ & $4 / 4$ & $5 / 4$ & 1.000 \\
Age, $\mathrm{y}$ & $49.5 \pm 1.6^{*}$ & $49.8 \pm 2.6$ & 0.9254 \\
Weight, $\mathrm{kg}$ & $92.2 \pm 9.7$ & $78.8 \pm 5.6$ & 0.2373 \\
Height, $\mathrm{cm}$ & $175 \pm 5$ & $168 \pm 3$ & 0.24 \\
$\mathrm{BMI} \mathrm{kg} / \mathrm{m}^{2}$ & $29.5 \pm 2.2$ & $27.7 \pm 1.8$ & 0.53 \\
$\mathrm{VO}_{2} \mathrm{max}, \mathrm{ml} / \mathrm{kg} / \mathrm{min}$ & $24 \pm 1.7$ & $22.9 \pm 1.9$ & 0.64 \\
\hline
\end{tabular}

*alues are mean \pm SEM 


\section{로을}

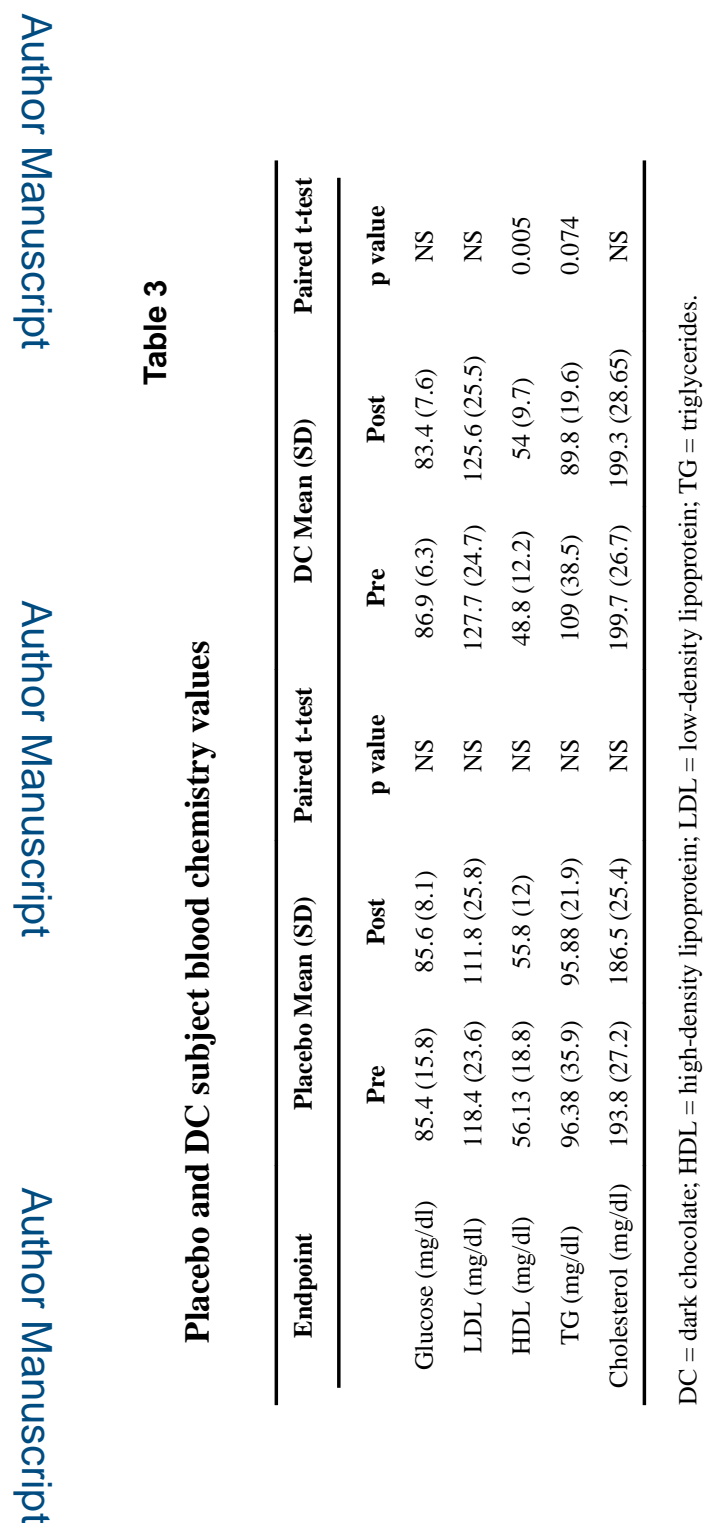

Food Funct. Author manuscript; available in PMC 2017 September 14. 